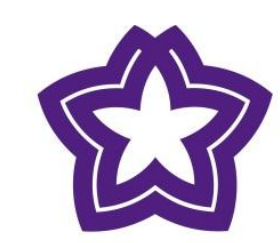

DALARNA

UNIVERSITY

Working papers in transport, tourism, information technology and microdata analysis

Out-of-town shopping and its induced CO2-emissions

Författare 1: Kenneth Carling

Författare 2: Johan Håkansson

Författare 3: Tao Jia

Nr: 2013:1

Editor: Hasan Fleyeh

Working papers in transport, tourism, information technology and microdata analysis

ISSN: 1650-5581

(C) Authors 


\title{
Out-of-town shopping and its induced $\mathrm{CO}_{2}$-emissions
}

\author{
Authors : Kenneth Carling, Johan Håkansson*, and Tao Jia
}

This version: 2013-01-07

\begin{abstract}
Planning policies in several European countries have aimed at hindering the expansion of out-of-town shopping centers. One argument for this is concern for the increase in transport and a resulting increase in environmental externalities such as $\mathrm{CO}_{2}$-emissions. This concern is weakly founded in science as few studies have attempted to measure $\mathrm{CO}_{2}$-emissions of shopping trips as a function of the location of the shopping centers. In this paper we conduct a counter-factual analysis comparing downtown, edge-of-town and out-of-town shopping. In this comparison we use GPS to track 250 consumers over a time-span of two months in a Swedish region. The GPS-data enters the Oguchi's formula to obtain shopping trip-specific $\mathrm{CO}_{2}$-emissions. We find that consumers' out-of-town shopping would generate an excess of 60 per cent $\mathrm{CO}_{2}$-emissions whereas downtown and edge-of-town shopping centers are comparable.
\end{abstract}

Key words: Car-specific $\mathrm{CO}_{2}$-emissions, Counter-factual, Dense network, GPS tracking, Regional shopping centers

- Kenneth Carling is a full professor in Statistics and Johan Håkansson is an associate professor in Human Geography at the School of Technology and Business Studies, Dalarna university, SE-791 88 Falun, Sweden. Tao Jia is an assistant professor in Geoinformatics at the School of Remote Sensing and Information Engineering, Wuhan University, China.

- Corresponding author, E-mail: jhk@du.se. Phone: +46-23-778573. 


\section{Introduction}

Consider the genesis of market places. Christaller in the 1930s (later published in English Christaller, 1966) formalized a geographical theory for their evolution. ${ }^{1}$ At the out-set he assumed the population to be uniformly distributed in an unbounded area and the effort of travelling to be equal in all directions on the plain. Both suppliers and consumers were assumed to act as Homo Economicus and market places emerged. The resulting distribution of the population was symmetric and the network homogenous, as illustrated in Figure 1. As a consequence, the network distance to the nearest market place for a consumer is perfectly correlated with the Euclidian distance in this idealized setting. Christaller found this idealized pattern to approximate well the observed pattern in the western part of Germany.

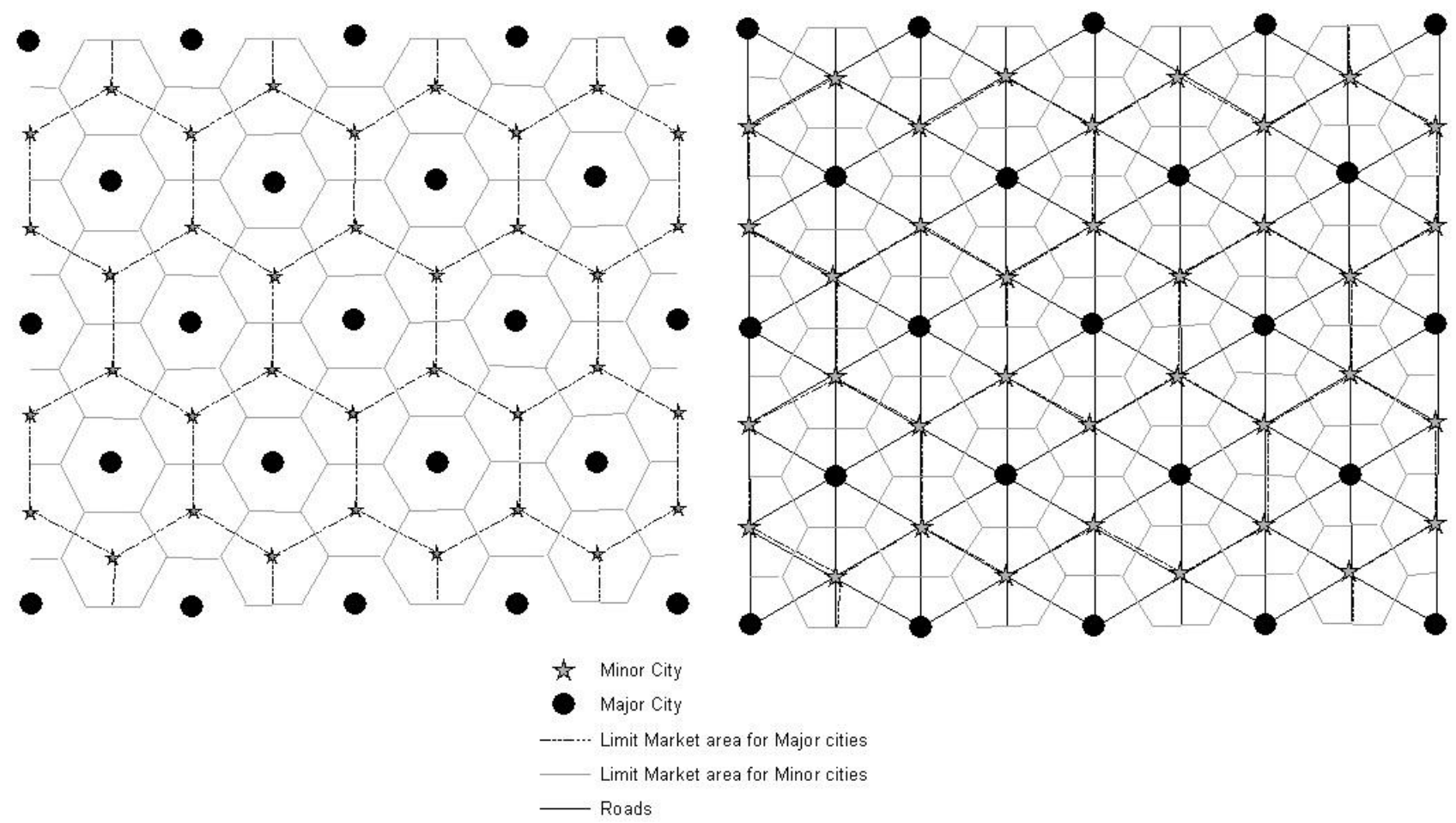

Figure 1: Christaller's landscape. The left panel shows the market area and how the population is distributed in the case of only two types, minor and major, of cities. The right panel adds the resulting network, assuming minimized transport costs.

In light of Christaller's theory, it is predictable that European cities would have the market place

\footnotetext{
${ }^{1}$ Christaller's theory was later challenged by further empirical examination of the pattern in other areas conducted by, among others, Lösch (1954) and Isard (1956). One reason for Christaller's theory as being incomplete is the assumption of transports made with equal effort in the plain. In many areas, this effort varies significantly and will give rise to heterogeneous networks serving non-symmetrically distributed populations.
} 
located in their downtown area. Furthermore, any market place located out-of-town ought to imply an increase in the effort of travelling. This line of reasoning is presumably an explanation why several European countries have obstructed out-of-town shopping centers. Williams (1995) summarize three arguments for obstructing out-of-town shopping in Great Britain. One is the increase in transports presumed to follow from out-of-town shopping (see also Barrett, 1995). The two other arguments are economic damage to down-town shopping and social impact on deprived social groups for which accessibility to out-of-town shopping may be limited (see also AlWaer, Sibley, and Lewis, 2008; Borgers and Vosters, 2011; Lang, 2012; Van der Krabben, 2009; Van Leeuwen and Rietveld, 2011).

In 1995, Williams (1995) referred to a report stating that an out-of-shopping center in Manchester would increase $\mathrm{CO}_{2}$-emissions by some remarkable 172 per cent. However, he doubted this estimate and pointed at the lack of research on the topic. Recently, AlWaer et al. (2008) repeat that the environmental impacts of out-of-town shopping remains a matter of belief rather than being grounded on empirical research.

The aim of this paper is to empirically evaluate $\mathrm{CO}_{2}$-emissions from consumers' car travel to shopping centers. The setting is the most central city of Borlänge in the Swedish region Dalecarlia some $300 \mathrm{~km}$ north-west of the capital Stockholm. We conduct an experiment where we compare the current edge-of-town shopping with counter-factual locations either downtown or out-of-town. The counter-factual analysis draws on the GPS-tracking of cars for 250 consumers in a time-span of March 2011 to May 2011.

This paper is organized as follows: section two presents the empirical setting, and section three gives the data and provides statistics on the consumers' shopping trips. The fourth section discusses how GPS-data converts into measurements of $\mathrm{CO}_{2}$-emissions and gives geographical information about the $\mathrm{CO}_{2}$-emissions of the shopping trips. The fifth section presents the results of the counter-factual analysis. The sixth section concludes this paper with a discussion. 


\section{Empirical setting}

Figure 2 shows the Dalecarlia region. The size of the region is approximately $31,000 \mathrm{~km}^{2}$. Figure $2 \mathrm{a}$ illustrates the distribution of its population. As of December 2010, the population numbers 277,000 residents. About $65 \%$ of the population lives in 30 towns and villages of between 1,000 and 40,000 residents, whereas the remaining third of the population resides in small, scattered settlements. The figure shows the distribution of the residents in the region by one-by-one kilometer squares.

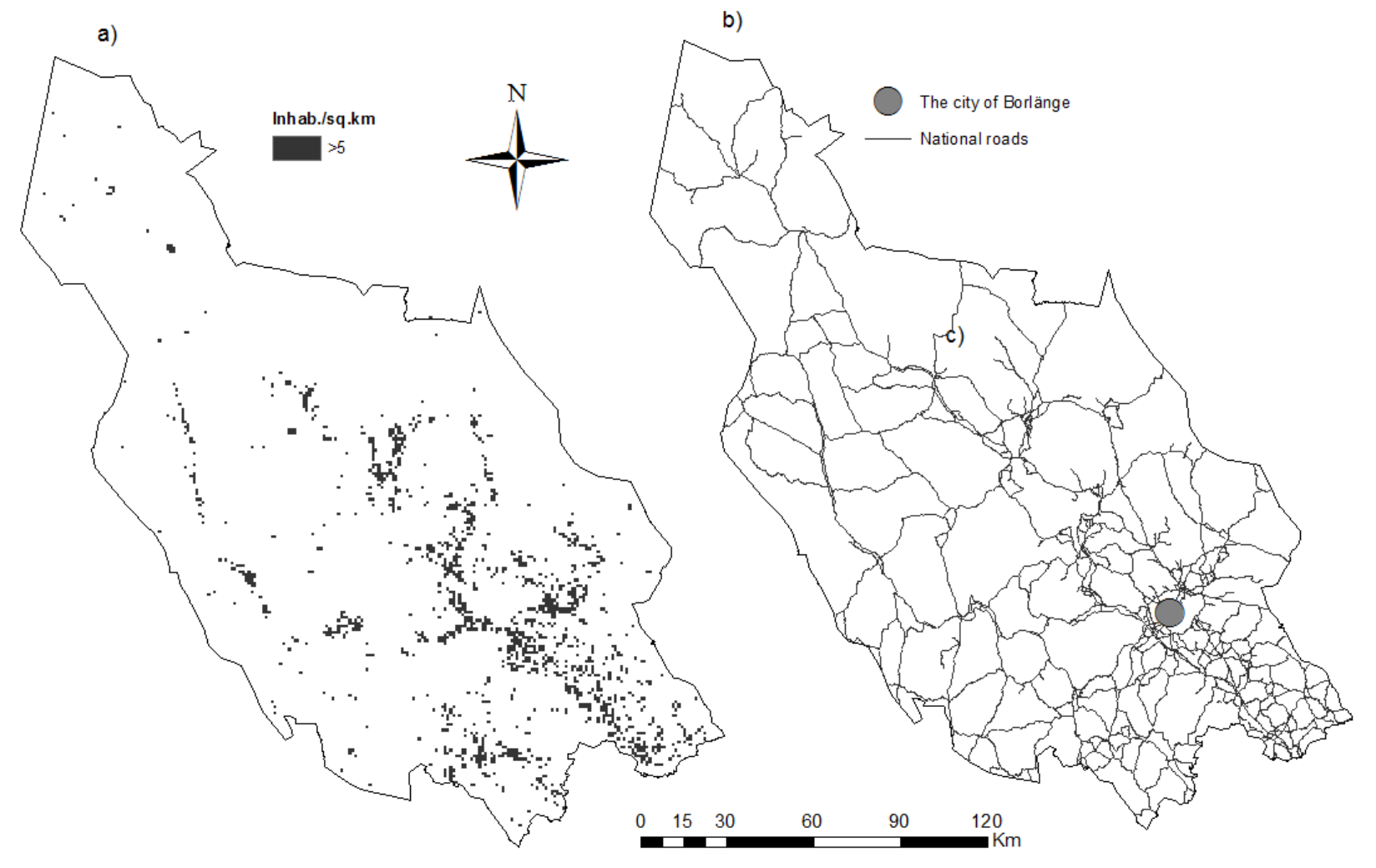

Figure 2: Map of Dalecarlia showing (a) one-by-one kilometer cells where the population exceeds 5 inhabitants and (b) national road system with the location of Borlänge imposed.

Figure $2 \mathrm{~b}$ shows the region's road network with a mark representing Borlänge city. Figure 2 indicates that the population is non-symmetrically distributed and that the network is heterogeneous, thus the region does not fit Christaller's idealization of the market place.

Carling, Han, and Håkansson (2012) found that Borlänge is the most accessible place in the region 
for car drivers. In fact, it is the preferred market place in the region for the retail industry. Figure 3 illustrates land use in Borlänge with three locations of shopping centers highlighted. Currently, most shopping takes place at an edge-of-town shopping center. During the course of some 30 years, shopping has transferred from the downtown center to this edge-of-town center such that the former is ten times downtown shopping. An alternative out-of-town shopping center is presently under consideration.

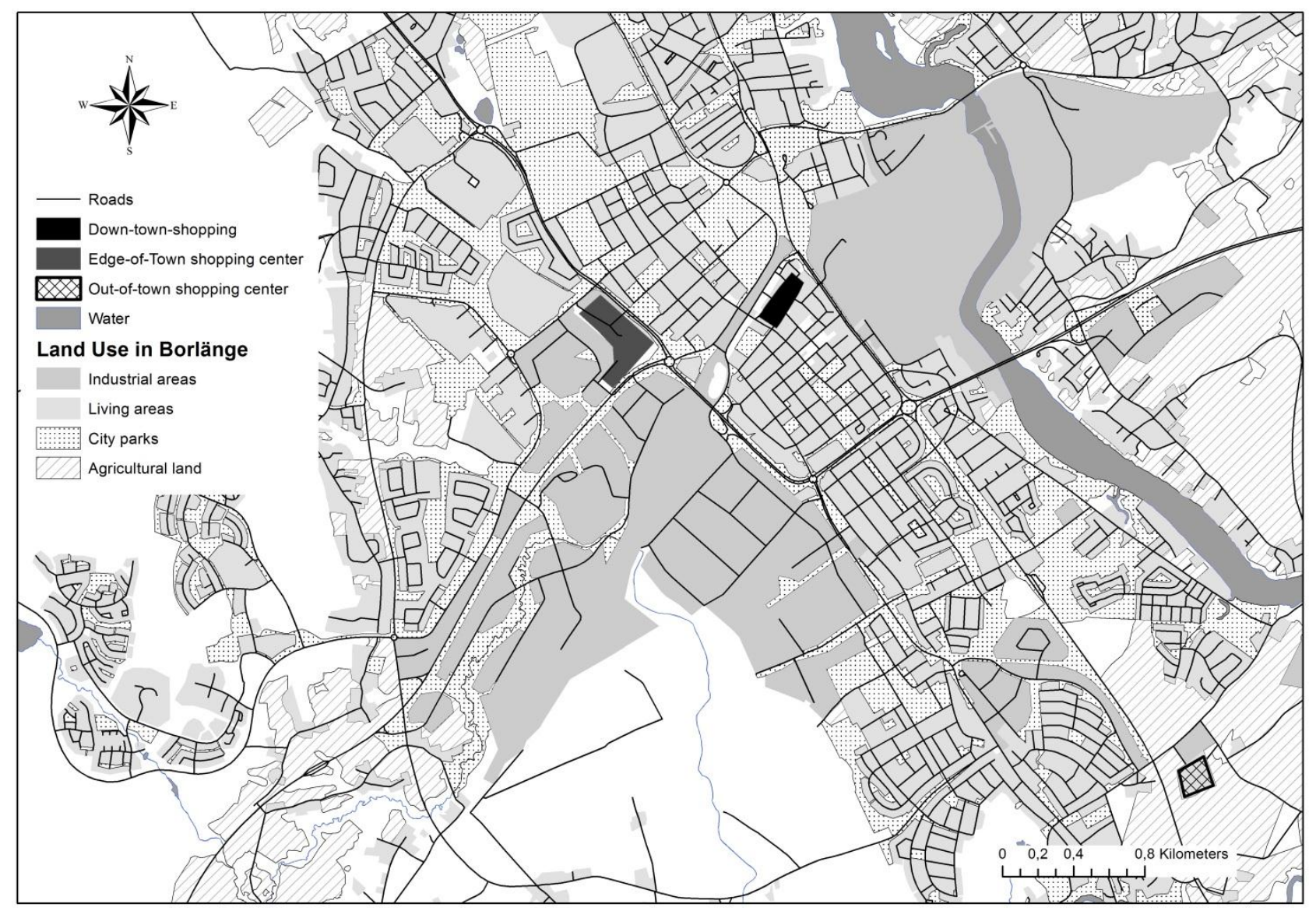

Figure 3: Map of land use in Borlänge highlighting downtown, edge-of-town and out-of-town shopping.

Borlänge is located at the edge of a plain with agricultural land and activities to the south and the east. The city is built up around a steel rolling mill on both sides of the Dalecarlia River and a large railway yard in the town's south-western part, and they act along with the river as barriers for the development of residential areas in the inner-city. As a consequence of the barriers, most residential areas are located in and are dispersed on the south-western side of the river with the downtown area between the steel mill and the railway yard. In addition, three suburban residential areas also belong to the city. One suburban residential area is located to the south-west of the center and two to the 
north-east with one on the north-eastern side of the river and the other some $5 \mathrm{~km}$ away from the center.

\section{Data}

Most studies of consumer behavior, including their travel patterns, are based on questionnaires or interviews. Moiseeva and Timmermans (2010) discuss data collection issues, including the use of tracking technologies. We simply note that it is difficult to obtain detailed and accurate documentation of travel patterns from questionnaires; instead we prefer measurements of the travelling pattern. We considered the idea of obtaining GPS-trackings of a sample of consumers. However, such recordings require the consent of the consumer which would most likely lead to substantial non-response if a random sample of the population were drawn. Instead we successfully negotiated a deal with four large sports associations (Domnarvets GOIF, Kvarnsveden Hockey, Stora Tuna IK and Torsångs IP) dispersed in Borlänge willing to recruit car-owning volunteers among their associates. Each association had a target of 75 volunteers that was almost met; in the end 250 volunteers with a proper home address participated in the study.

Each volunteer was equipped with BT-338X, a Bluetooth GPS data logger, that combines a GPS receiver and a data logger with a Bluetooth interface was used to record volunteers' daily in-car movements. The 89 BT-338X were shared among the volunteers, according to a protocol, and attached to the private car of the volunteer for two by one week. The data collection lasted from March 29 to May 15 in 2011. In total, we obtained a dataset that included 250 GPS logger files recording 262,021 movements with the removal of 5,402 invalid records due GPS-signal being lost.

The GPS logger file contained the movements of one volunteer. Each record in the GPS logger file contained information of when the GPS signal was received (every 5 or 30 seconds), and the location regarding longitude and latitude, as well as the velocity. ${ }^{2}$ The GPS were set to receive a signal every 5 or 30 seconds, varying across volunteers. However due to interference, the time between signals varied to some extent where about 45 per cent of the recordings were in five seconds interval and longer for the remaining intervals.

\footnotetext{
2 The longitude and latitude are referenced using the World Geodetic System 84 (WGS 84) and measured with the accuracy of five meters according to the BT-338X user manual.
} 


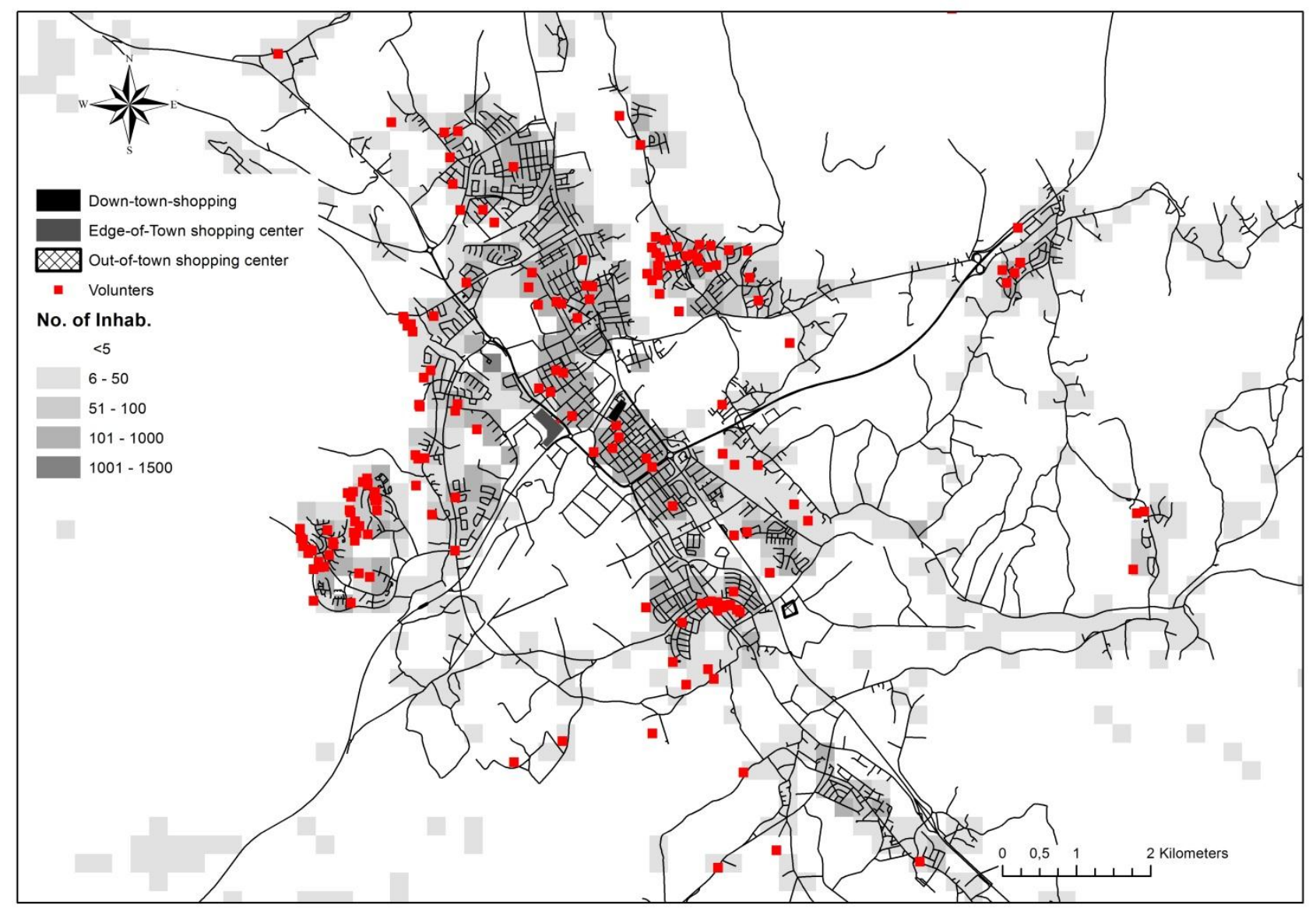

Figure 4: Spatial distribution of the volunteers as well as for the population in Borlänge.

A question is, of course, to what extent do the volunteers represent the spatial distribution of consumers in Borlänge? Figure 4 shows the residence of volunteers as well as the distribution of the population in the city. As can be seen from Figure 4, the volunteers are spread out in the city in a pattern similar to the overall population's settlement. The population is more concentrated in the center most area than the volunteers. This presumably may be explained by the requirement that volunteers should be in possession of a car.

The volunteers made some 5,600 trips during the study period. Figure 5 illustrates how the trips were distributed on the street network of Borlänge. For a large part of the streets we have high trip flows. Understandably, trips are heavily concentrated to a few expressways. Note also that there are arterial streets in the residential areas as well as private roads with no or very low trip flows. 


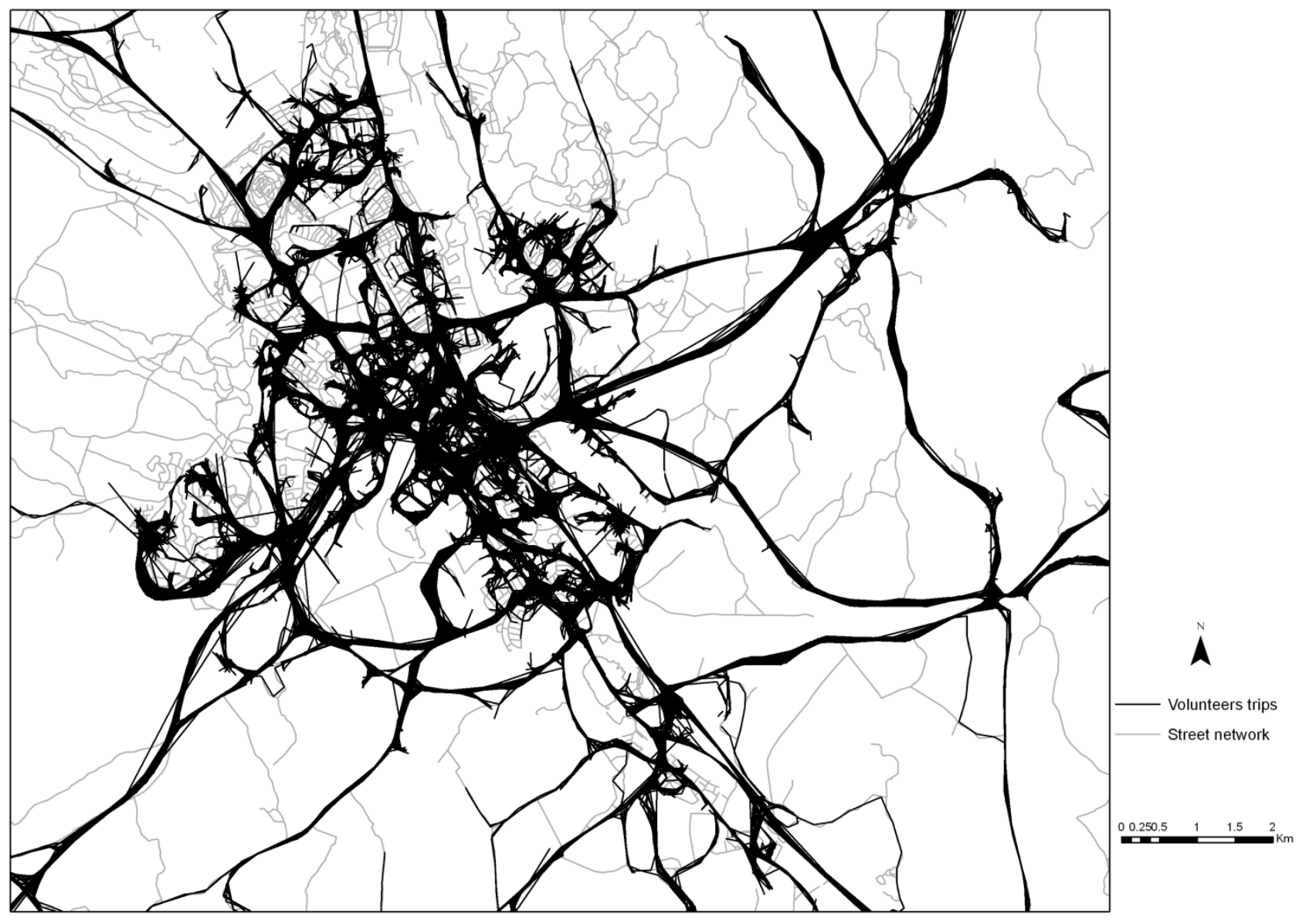

Figure 5: Trip flows in Borlänge for the volunteers in the spring of 2011.

Most trips ${ }^{3}$ were unrelated to shopping. 498 trips were to the edge-of-town shopping center with a total trip length of 2,481 kilometers conducted by 151 of the 250 volunteers. ${ }^{4}$ During the study period, the median number of trips per volunteer was three while one volunteer made as many as 12 trips to the shopping center. Jia, Jiang, Carling, Bohlin and Ban (2012a) found that the average number of halts per trip for all the volunteers' trips was about seven. However, the shopping trips were mostly directly from homes in the residential areas of Borlänge (Figure 6). The in- and out-flow of other commercial areas was one exception. Overall, the shopping center attracts consumers from all parts of the city.

\footnotetext{
${ }^{3}$ Details on how the GPS records were used for constructing trips and additional information about the volunteers driving is provided in Jia, Carling, and Håkansson (2012b).

${ }^{4}$ A small fraction of shopping trips frequented the downtown center and the yet unexploited out-of-town center.
} 


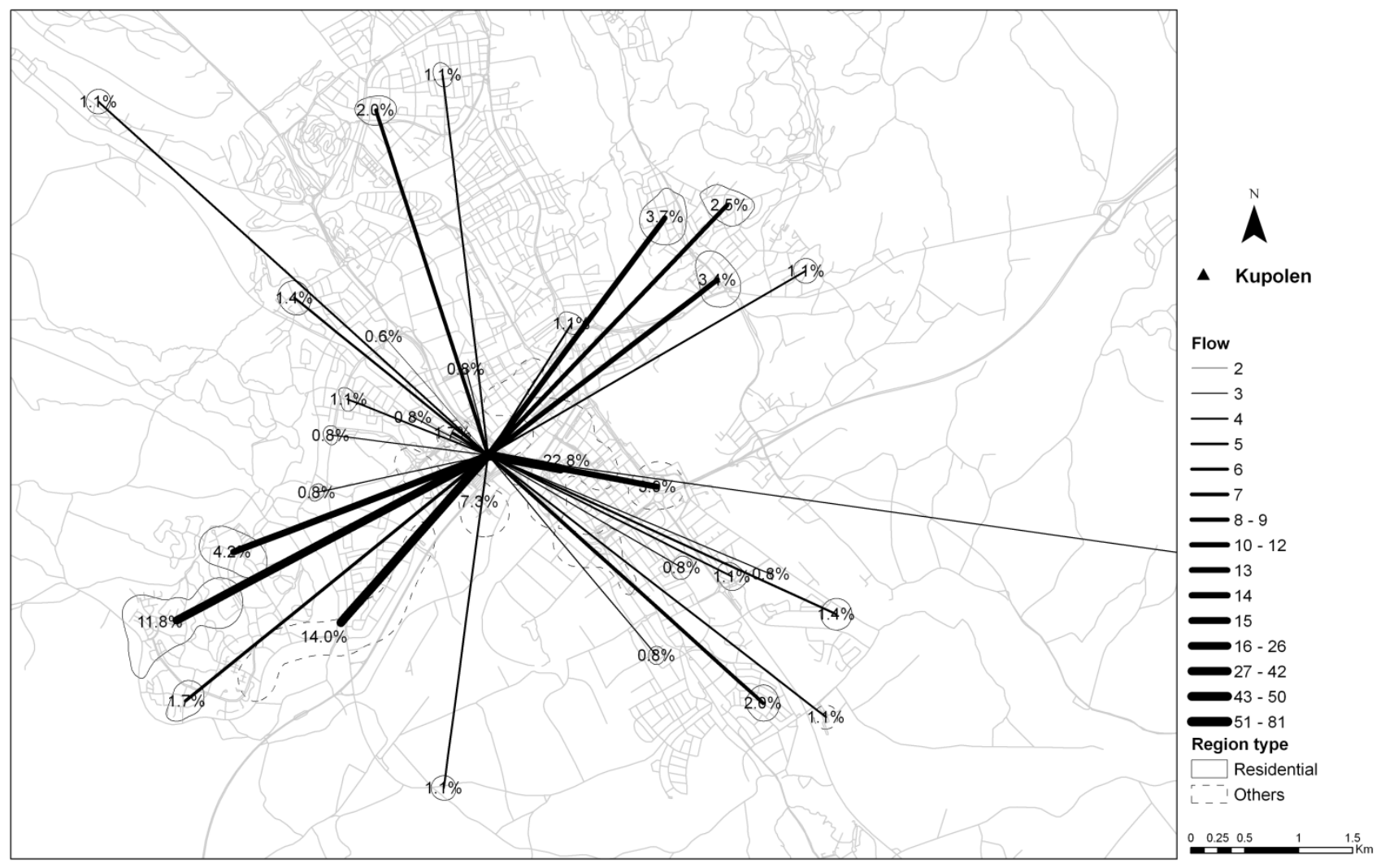

Figure 6: Flow map of trips to the edge-of-town shopping center.

\section{Measuring $\mathrm{CO}_{2}$-emissions}

It is well known that trips consume energy regardless of the transportation mode such as walking, biking or travelling by car or bus. There are also associated externalities from the emissions of environmental pollutants such as carbon-dioxide, nitrogen-oxide, and particulates. In the interest of reducing externalities, several studies have tried to establish the relationship between trip patterns and transport emissions. For example, Redsell, Lucas, and Ashford (1988) reported that an average vehicle speed of $65 \mathrm{~km} / \mathrm{h}$ give the lowest consumption of energy for petrol cars. Furthermore, based on data from the 1989-1991 National Travel Survey, Stead (1999) suggested travel length as a proxy for vehicle emissions because of the ease in collecting and computing it, whereas Carling, Håkansson, and Rudholm (2012) used travel length as a proxy for $\mathrm{CO}_{2}$-emissions in an examination of optimal location of retail stores.

However, travel length might be over-simplistic in estimating transport emissions as other factors such as speed, time, acceleration, deceleration, road and weather conditions, and types of driver and 
vehicle are ignored. To improve the assessment of emissions, a few on-road vehicle emission models have been proposed in the literature such as the IVE model (Davis, Lents, Osses, Nikkila, and Barth, 2005), the eco-driving model (Ando and Nishihori, 2012), and LIISA (Technical Research Center of Finland, see Määttä-Juntunen, Antikainen, Kotavaara, and Rusanen, 2011).

While Stead's (1999) model might be overly simplistic for the problem at hand, Davis et al (2005) is prohibitively complex in that it adopts binning technology with both the micro-working conditions of vehicles and the surrounding environmental factors like wind direction and road slope. A reasonable model for our GPS-data is one developed and tested by Oguchi, Katakura, and Taniguchi (2002) specifically for gasoline-powered vehicles. Their model estimates the $\mathrm{CO}_{2}$-emissions for a single trip as:

(1) $E=K_{c} \times\left\{0.3 T+0.028 D+0.056 \sum_{i=2}^{n} 1\left[v_{i}>v_{i-1}\right] \times\left(v_{i}^{2}-v_{i-1}^{2}\right)\right\}$,

where $E$ is the estimated trip-specific $\mathrm{CO}_{2}$-emissions $(\mathrm{kg}), K_{c}$, the $\mathrm{CO}_{2}$-emission coefficient, taking on the value $0.002322, T$ is travel time (in seconds), $D$ is travel length (in meters), $v^{i}$ the velocity $(\mathrm{m} / \mathrm{s})$ of the vehicle at GPS location $i, n$ is the number of GPS locations of the trip, and 1[·] an indicator function being one if true and zero otherwise.

Figure 7 shows $\mathrm{CO}_{2}$-emissions along the street network in Borlänge at three levels: low indicates the 50 per cent of streets with the lowest emissions, high indicates the 20 per cent of streets with the highest emissions, and medium are the remaining streets. Figure $7 \mathrm{a}$ shows the total $\mathrm{CO}_{2}$-emissions per street from all of the 5,600 trips (cf Figure 5). Obviously, emissions are high at the most frequented streets. However, Figure $7 \mathrm{~b}$ provides a complementary understanding of local emissions. In this figure, the amount of emissions is standardized by the number of passing vehicles and the length of the street. Emissions are generally low on larger roads with marked exceptions at roundabouts and intersections. Emissions are high at arterial streets in residential areas. 

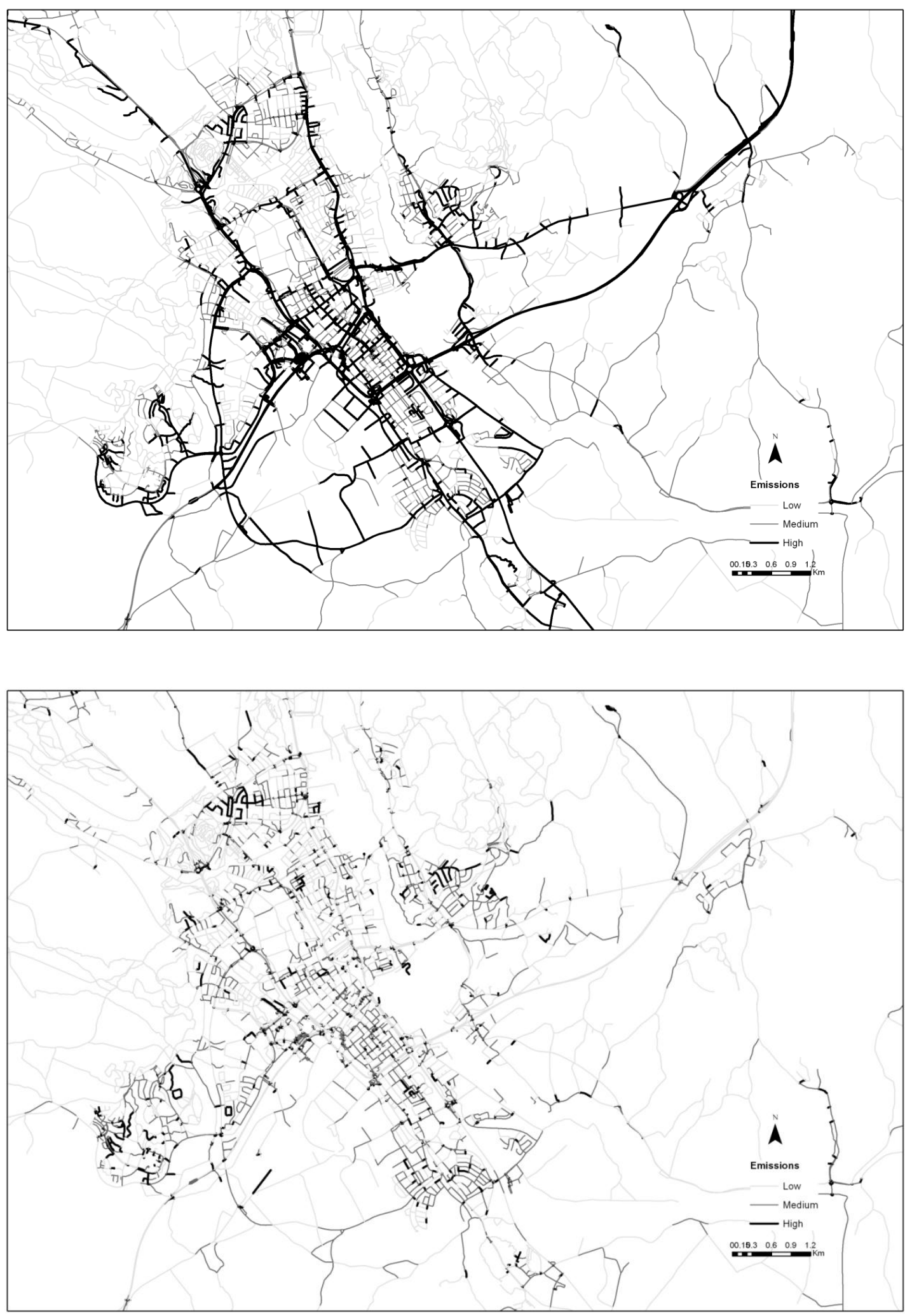

Figure 7: Map of local streets in Borlänge. Induced (a) total $\mathrm{CO}_{2}$-emissions by the volunteers' car trips and (b) standardized by the number of passing vehicles of volunteers in the spring of 2011.

Hence, the street network is heterogeneous with regards to emission-levels implying that it will 
matter whether the consumers opt for the fastest, shortest or least emitting route when patronizing a shopping center. In the counter-factual analysis, we stipulate that consumers opt for the shortest route. We believe this choice to be the most plausible since we think that very few consumers are aware of the how their choice of route in the city correlates with $\mathrm{CO}_{2}$-emissions. In addition to this Jia et al (2012b) found a correlation of 0.96 between $\mathrm{CO}_{2}$-emissions of actual trip and a shortest path trip.

In the counter-factual analysis, we wanted to assess the magnitude of $\mathrm{CO}_{2}$-emissions for different locations of a shopping center. This is readily done by computing a consumer's trip emissions to each of the competing locations and then sum over all consumers. We have observed, by GPS tracking, the induced $\mathrm{CO}_{2}$-emissions between many routes in the city as evident from Figure 5, but not for all of them. For each consumer we require the $\mathrm{CO}_{2}$-emissions for three routes i.e. the shortest route to down-town, the edge-of-town, and the out-of-town locations from the home. Figure $7 \mathrm{~b}$ implies an estimate of $\mathrm{CO}_{2}$-emissions per road segment and trip. This estimate is used for summing the emissions of relevant road segments in the shortest route to the location of interest for each consumer's trip.

To verify this method of estimating emissions for the counter-factual analysis we did the following check. We picked the 498 trips of volunteers observed to travel to the edge-of-town shopping center. For each trip we have the $\mathrm{CO}_{2}$-emissions as implied by the Oguchi-formula. These values were correlated to the estimated emissions from the method described above for the very same 498 trips. The correlation was as high as 0.78 despite not all observed trips being the shortest route and the inherent variation in driving pattern of the same route from one time to another.

\section{Results}

We considered including all residents of Borlänge in the counter-factual analysis. However there are two reasons why we choose not to. We only had the residents in the city geo-coded with a precision of 175 meters, and furthermore we could not identify car-owning residents. Instead the counter-factual analysis refers to the volunteers and their observed frequency of (shopping) trips. 
In Table 1, the outcomes are shown for the three locations of a shopping center. In computing the outcomes, it is assumed that the volunteers make equally as many trips to the shopping center. The shortest route distance to the downtown and edge-of-town locations are similar whereas the out-of-town location is 64 per cent further away from a downtown location. This extension in distance transforms in an increase in shopping related emissions by nearly 60 per cent. From Eq. (1) it is obvious that acceleration induces much emission, and we therefore include statistics for the number of intersections along the route. The rate of intersections by travelled kilometer is higher to the downtown location than to the out-of-town location providing a partial explanation as to why the difference in emissions ( 60 per cent) is smaller than the one in travel length (64 per cent).

The foundation for statistical inference in this case is a bit weak since the observations do not come from a random sample. However, the implied standard errors of the mean of $\mathrm{CO}_{2}$-emissions are about 0.01 (and even smaller for a pair-wise comparison) making the difference between downtown and edge-of-town insignificant.

Table 1: Counter-factual analysis for the 250 volunteers setting one trip per volunteer. Standard deviations are in parentheses.

\begin{tabular}{|lccc|}
\hline \hline & & \multicolumn{2}{c|}{ Location of shopping center } \\
Outcome & Down-town & Edge-of-town & Out-of-town \\
\cline { 2 - 4 } \# trips & 250 & 250 & 250 \\
Average \# of intersections & 49 & 50 & 58 \\
Average distance $(\mathrm{km})$ & 3.88 & 4.03 & 6.35 \\
Average $\mathrm{CO}_{2}$-emission & $0.27(0.16)$ & $0.28(0.13)$ & $0.43(0.19)$ \\
\hline
\end{tabular}

The assumption that the volunteers make equally as many shopping trips violates the observed pattern. Table 2 shows the outcome of the counter-factual analysis where this assumption is relaxed. In the analysis, each volunteer is weighted with his observed number of shopping trips. The 99 volunteers who were not observed to making a shopping trip during the study period were assigned a weight as if they did one trip. This analysis, which implies a more realistic modeling of the consumer's shopping trip behavior, confirms the findings in Table 1. The Table 3 provides the outcome when it is assumed that all trips by the volunteers were for the purpose of shopping. This is of course far-fetched, but nonetheless the same outcome is noted as in Tables 1-2. 
Table 2: Counter-factual analysis for the 250 volunteers with the number of shopping trips according to the observed pattern. Standard deviations are in parentheses.

\begin{tabular}{|lccc|}
\hline \hline & & \multicolumn{2}{c|}{ Location of shopping center } \\
Outcome & Down-town & Edge-of-town & Out-of-town \\
\cline { 2 - 4 } \# trips & 597 & 597 & 597 \\
Average \# of intersections & 54 & 51 & 60 \\
Average distance $(\mathrm{km})$ & 4.06 & 4.04 & 6.56 \\
Average $\mathrm{CO}_{2}$-emission & $0.30(0.16)$ & $0.30(0.13)$ & $0.47(0.19)$ \\
\hline
\end{tabular}

Table 3: Counter-factual analysis for the 250 volunteers assuming all their trips to be shopping related. Standard deviations are in parentheses.

\begin{tabular}{|lccc|}
\hline \hline & & \multicolumn{2}{c|}{ Location of shopping center } \\
Outcome & Down-town & Edge-of-town & Out-of-town \\
\cline { 2 - 4 } \# trips & 5599 & 5599 & 5599 \\
Average \# of intersections & 50 & 50 & 58 \\
Average distance $(\mathrm{km})$ & 3.86 & 4.00 & 6.17 \\
Average $\mathrm{CO}_{2}$-emission & $0.27(0.16)$ & $0.28(0.12)$ & $0.43(0.19)$ \\
\hline
\end{tabular}

\section{Concluding discussion}

We have considered the question whether out-of-town shopping centers induce excess in $\mathrm{CO}_{2}$-emissions. This is a controversial issue for many governments and local authorities around Europe. The literature notes that the issue is based on belief rather than empirical findings. We contribute by empirically showing that an out-of-town shopping center would increase emissions by some 60 per cent in the city Borlänge, Sweden. To what extent does this finding extrapolate to other settings?

Firstly, we are aware of one study that addresses this question empirically by considering travelling behavior. Määttä-Juntunen et al (2011) also found edge-of-town locations preferable to out-of-town locations although they did not have access to GPS tracking data. In contrast to our study, they studied a Finnish town by the sea with low-lands to the east and a quite different spatial configuration of consumers. However, studies of other spatial configurations would be useful for a more complete understanding of environmental impacts of out-of-town shopping. While waiting for such contributions, we have outlined a method for conducting studies of this kind.

Secondly, $\mathrm{CO}_{2}$-emissions related to shopping also occur because of the supply of goods to the 
shopping center and the operation of it. We are not aware of any public studies of these two issues. We have insufficient knowledge of emissions resulting from the operation of shopping centers, but note in Borlänge both the edge-of- and downtown areas are easily accessed by train and truck.

Thirdly, we assume that consumers follow the shortest route between their homes and a shopping center. The shortest route is apparently a good approximation to actual driving behavior (see Jia et al, 2012b). However, consumers often have several purposes for a trip (Carling and Håkansson, 2012 and references therein). The consideration of multi-purpose trips would most likely render the out-of-town location even less appealing as locations for other purposes lay primarily in the edge-of-town and downtown areas in Borlänge.

\section{Acknowledgements}

Financial support from the Swedish Retail and Wholesale Development Council is gratefully acknowledged. We are grateful to Magnus Bohlin who managed the recruitment and instructions of volunteers.

\section{References}

AlWaer, H., Sibley, M., and Lewis, J., (2008). Factors and Priorities for Assessing Sustainability of Regional Shopping Centres in the UK, Architectural Science Review, 51.4, 391-402.

Ando, R., and Nishihori, Y., (2012). A study on factors affecting the effective eco-driving, Procedia Social and Behavioral Sciences, 54:4, 27-36.

Barrett, G.M.J., (1995). Transport emissions and travel behaviour: A critical review of recent European Union and UK policy initiatives, Transportation 22, 295-323.

Borgers, A., and Vosters, C., (2011). Assessing preferences for mega shopping centres: A conjoint measurement approach, Journal of Retailing and Consumer Services, 18, 322-332.

Carling K., Han M., and Håkansson J, (2012). Does Euclidean distance work well when the p-median model is applied in rural areas?, Annals of Operations Research, 201, 83-97.

Carling K., and Håkansson J, (2012). A compelling argument for the gravity p-median model, European Journal of Operational Research, Online Dec 3.

Carling, K., Håkansson, J., and Rudholm, N., (2012). Optimal retail location and CO2 emissions, 
Working papers in transport, tourism, information technology and microdata analysis, 2012:05.

Christaller, W., (1966). Central places in central Germany. C. W. Baskin, trans. Englewood Cliffs, N.J.: Prentice-Hall.

Davis, N., Lents, J., Osses, M., Nikkila, N., and Barth, M., (2005). Development and application of an international vehicle emissions model, Transportation Research Board 81 ${ }^{\text {st }}$ Annual Meeting, Washington D.C.

Isard, W., (1956). Location and Space Economy, Wiley.

Jia T., Jiang B., Carling K., Bohlin M. and Ban Y. (2012a). An empirical study on human mobility and its agent based modeling, Journal of Statistical Mechanics: Theory and Experiment, P11024.

Jia, T., Carling, K., and Håkansson, J. (2012b). Trips and their CO2 emissions induced by a shopping center, Working papers in transport, tourism, information technology and microdata analysis, 2012:XX.

Lang, A., (2012). City Retailers' Perceptions of Competition: A Choice Experiment, HUI Working Papers 58.

Lösch, L. J., (1954). The Economics of Location, Yale University Press, New Haven, Connecticut.

Määttä-Juntunen, H., Antikainen, H., Kotavaara, O., and Rusanen, J., (2011). Using GIS tools to estimate $\mathrm{CO} 2$ emissions related to the accessibility of large retail stores in the Oulu region, Finland, Journal of Transport Geography 19, 346-354.

Moiseeva, A., and Timmermans, H., (2010). Imputing relevant information from multi-day GPS tracers for retail planning and management using data fusion and context-sensitive learning, Journal of Retailing and Consumer Services 17:3, 189-199.

Oguchi, T., Katakura, M., and Taniguchi, M., (2002). Carbon-dioxide emission model in actual urban road vehicular traffic conditions, Journal of Infrastructure Planning and Management, 695, 125-136.

Redsell M., Lucas, G., and Ashford, N., (1988). Comparison of on-road fuel consumption for diesel and petrol cars, Transport and Road Research Laboratory Contractor Report 79, TRRL, Crowthorne.

Stead, D., (1999). Relationships between transport emissions and travel patterns in Britain, Transport Policy, 6, 247-258.

Van der Krabben, E., (2009). Retail Development in The Netherlands: Evaluating the Effects of Radical Changes in Planning Policy, European Planning Studies, 17:7, 1029-1048.

Van Leeuwen, E.S., and Rietveld, P., (2011). Spatial Consumer Behaviour in Small and Medium-sized Towns, Regional Studies, 45:8, 1107-1119.

Williams, C.C., (1995). Opposition to regional shopping centres in Great Britain: a clash of cultures?, Journal of Retailing and Consumer Services, 2:4, 241-249. 